\title{
Molecular analysis of phosphomannomutase (PMM) genes reveals a unique PMM duplication event in diverse Triticeae species and the main PMM isozymes in bread wheat tissues
}

Chunmei Y ${ }^{1,2,3}$, Yiwen $\mathrm{Li}^{1}$, Bin Li ${ }^{1,3}$, Xin Liu', Lifang Hao ${ }^{1,3}$, Jing Chen ${ }^{1,3}$, Weiqiang Qian ${ }^{1,3}$, Shiming $\mathrm{Li}^{1,3}$, Guanfeng Wang ${ }^{1,3}$, Shiwei Bai ${ }^{1,3}$, Hua Ye ${ }^{1,3}$, Huanju Qin', Qianhua Shen ${ }^{1}$, Liangbiao Chen ${ }^{1}$, Aimin Zhang ${ }^{1}$, Daowen Wang ${ }^{1 *}$

\begin{abstract}
Background: Phosphomannomutase (PMM) is an essential enzyme in eukaryotes. However, little is known about PMM gene and function in crop plants. Here, we report molecular evolutionary and biochemical analysis of PMM genes in bread wheat and related Triticeae species.

Results: Two sets of homoeologous PMM genes (TaPMM-1 and 2) were found in bread wheat, and two corresponding PMM genes were identified in the diploid progenitors of bread wheat and many other diploid Triticeae species. The duplication event yielding PMM-1 and 2 occurred before the radiation of diploid Triticeae genomes. The PMM gene family in wheat and relatives may evolve largely under purifying selection. Among the six TaPMM genes, the transcript levels of PMM-1 members were comparatively high and their recombinant proteins were all enzymatically active. However, PMM-2 homoeologs exhibited lower transcript levels, two of which were also inactive. TaPMM-A1, B1 and D1 were probably the main active isozymes in bread wheat tissues. The three isozymes differed from their counterparts in barley and Brachypodium distachyon in being more tolerant to elevated test temperatures.

Conclusion: Our work identified the genes encoding PMM isozymes in bread wheat and relatives, uncovered a unique PMM duplication event in diverse Triticeae species, and revealed the main active PMM isozymes in bread wheat tissues. The knowledge obtained here improves the understanding of PMM evolution in eukaryotic organisms, and may facilitate further investigations of PMM function in the temperature adaptability of bread wheat.
\end{abstract}

\section{Background}

Phosphomannomutase (PMM, EC 5.4.2.8), catalyzing the interconversion between mannose-6-phosphate and mannose-1-phosphate, is an essential and conserved enzyme in eukaryotic organisms [1,2]. Mannose-1-phosphate is necessary for synthesizing the vital cellular metabolite GDP-mannose, which plays a crucial role in the formation of polysaccharide chains required for the

\footnotetext{
* Correspondence: dwwang@genetics.ac.cn

${ }^{1}$ The State Key Laboratory of Plant Cell and Chromosome Engineering, Institute of Genetics and Developmental Biology, Chinese Academy of Sciences, Beijing 100101, PR China

Full list of author information is available at the end of the article
}

glycosylation of protein and lipid molecules [3,4]. In higher plants, GDP-mannose also acts as an important precursor for the biosynthesis of the key antioxidant ascorbic acid (AsA) [5,6], and the mannose containing polysaccharides are essential for the development of functional cell walls [2,4]. From available information, the copy number of functional $P M M$ in diploid eukaryotic species varies from one (i.e., in Saccharomyces cerevisiae and Arabidopsis thaliana) to two (e.g., in human). PMM proteins from different eukaryotic species are highly similar in primary structure, with more than $50 \%$ amino acid sequence identities found among the PMMs 
from S. cerevisiae, Arabidopsis and human [6]. The crystal structure and catalytic mechanism of mammalian PMMs are well understood [7], and there is also a wealth of information on human PMM2, whose point mutations lead to a genetically inherited disease CDG-Ia [8-11].

Two recent molecular genetic studies in Arabidopsis show that defect in $P M M$ function reduces AsA biosynthesis and protein glycosylation, causing enhanced susceptibility to oxidation stress and plant death at high growth temperature $\left(28^{\circ} \mathrm{C}\right)[6,12]$. The requirement of a functional PMM protein for Arabidopsis to grow at $28^{\circ} \mathrm{C}$ is consistent with the pioneering finding of temperature sensitive PMM mutations that arrest $S$. cerevisiae growth at $37^{\circ} \mathrm{C}[1]$, suggesting that $\mathrm{PMM}$ may be generally important for the temperature adaptability of eukaryotes.

Compared to the above progress, little is known about $P M M$ gene and function in crop plants, although broad temperature adaptability is vitally important for crops to achieve high yield potential under diverse environmental conditions. To improve our understanding on $P M M$ in crop plants, we have embarked on a systematic molecular and biochemical analysis of $P M M$ genes in bread wheat (T. aestivum, $2 \mathrm{n}=6 \mathrm{x}=42$, AABBDD), a polyploid crop species cultivated in both temperate and tropical regions and with harvest possible under a wide range of temperature conditions $[13,14]$. Bread wheat belongs to the tribe Triticeae, which is composed of approximately 350 species, and contains both diploid (such as barley and rye) and polyploid (e.g., bread wheat) crop plants [15]. The diploid genomes in Triticeae species are homoeologous, and may be combined to form polyploids through natural and artificial hybridizations [16]. Bread wheat was evolved through natural hybridization between tetraploid wheat ( . turgidum, $2 \mathrm{n}=4 \mathrm{x}=28$, AABB) and Aegilops tauschii $(2 \mathrm{n}=2 \mathrm{x}=14, \mathrm{DD})$ about 8000 years ago [16-18]. T. turgidum was formed about 0.5 million years ago (MYA) through spontaneous hybridization between an unidentified Triticeae species containing the B genome and the wild einkorn wheat $T$. urartu $(2 \mathrm{n}=2 \mathrm{x}=14$, AA) [19-22]. The A, B and D genomes diverged from each other around 2.5 to 4.5 MYA, whereas the divergence of wheat and barley occurred around 11 MYA [19-22]. Although bread wheat and related Triticeae species generally contain large and complex genomes, the advent of structural and functional genomics research in model cereals (rice, Brachypodium distachyon) has made it possible to conduct relatively detailed molecular genetic and biochemical studies of important genes both within Triticeae and among rice, Brachypodium and Triticeae species. The genomic resources of rice and $B$. distachyon (e.g., molecular markers, annotated genomic information) have both been proved to be very useful in the investigations of important Triticeae genes, such as Ph1 and Lr34/Yr18 in common wheat and Ppd-H1 and Cly1 in barley [23-26].

From the information presented above, the main objectives of this work were to 1) determine PMM genes and loci in bread wheat and related Triticeae species, and 2) investigate the evolution of Triticeae PMM genes and the main active PMM isozymes in bread wheat tissues, with the aid of the genomic knowledge of rice and $B$. distachyon.

\section{Results}

Isolation and characterization of PMM genes

Two approaches (bioinformatic analysis, molecular cloning) were used to identify and isolate the $P M M$ genes in B. distachyon, bread wheat and related Triticeae species (barley, T. urartu, T. turgidum, Ae. tauschii). In total, 17 distinct $P M M$ coding sequences were isolated (Table 1).

Table 1 PMM genes from $B$. distachyon, bread wheat and related Triticeae species, and rice ${ }^{a}$

\begin{tabular}{|c|c|c|c|c|c|}
\hline Species & Gene & $\begin{array}{l}\text { gDNA } \\
\text { (bp) }\end{array}$ & $\begin{array}{l}\text { CDNA } \\
\text { (bp) }\end{array}$ & ORF & $\begin{array}{l}\text { Protein } \\
\text { (aa) }\end{array}$ \\
\hline $\begin{array}{l}\text { Brachypodium distachyon } \\
(\mathrm{Bd} 21)^{\mathrm{b}}\end{array}$ & $B d P M M$ & 2696 & 750 & + & 249 \\
\hline Barley (Hordeum vulgare) & HVPMM-1 & 2185 & 750 & + & 249 \\
\hline (Betzes) & HVPMM-2 & 3263 & 771 & $-^{c}$ & - \\
\hline Triticum urartu & TUPMM-A1 & 2228 & 750 & + & 249 \\
\hline (DV877 and IE29-1) & TUPMM-A2 & 2542 & 751 & $-{ }^{d}$ & - \\
\hline Aegilops tauschii & $\begin{array}{l}\text { AetPMM- } \\
\text { D1 }\end{array}$ & 2409 & 759 & + & 252 \\
\hline (AS67 and AS91) & $\begin{array}{l}\text { AetPMM- } \\
\text { D2 }\end{array}$ & 2348 & 756 & + & 251 \\
\hline $\begin{array}{l}\text { Triticeae turgidum ssp. } \\
\text { durum }\end{array}$ & TtPMM-A1 & 2227 & 750 & + & 249 \\
\hline \multirow[t]{3}{*}{ (Langdon) } & TtPMM-A2 & 2781 & 752 & $-{ }^{d}$ & - \\
\hline & TtPMM-B1 & 2256 & 750 & + & 249 \\
\hline & TtPMM-B2 & 2500 & 747 & + & 248 \\
\hline $\begin{array}{l}\text { Bread wheat (Triticum } \\
\text { aestivum) }\end{array}$ & TaPMM-A1 & 2225 & 750 & + & 249 \\
\hline \multirow{5}{*}{$\begin{array}{l}\text { (Xiaoyan 54, Chinese } \\
\text { Spring) }\end{array}$} & TaPMM-A2 & 2778 & 751 & $-{ }^{d}$ & - \\
\hline & TaPMM-B1 & 2256 & 750 & + & 249 \\
\hline & TaPMM-B2 & 2500 & 747 & + & 248 \\
\hline & TaPMM-D1 & 2409 & 759 & + & 252 \\
\hline & TaPMM-D2 & 2346 & 756 & + & 251 \\
\hline $\begin{array}{l}\text { Rice (Oryza sativa ssp. } \\
\text { japonica) } \\
\text { (Nipponbare) }\end{array}$ & OsPMM & $e^{2466}$ & $747^{f}$ & + & 248 \\
\hline
\end{tabular}

a The genomic DNA (gDNA) and cDNA sequences include start (ATG) and stop (TGA) codons.

b Plant materials from which PMM sequences were isolated.

c ORF disrupted by premature stop codon.

d ORF interrupted by frameshift mutation.

e The chromosomal locus containing OsPMM genomic sequence is Os04g0682300.

${ }^{f}$ The GenBank accession number for OsPMM cDNA is DQ442996. 
A single $P M M$ gene was found for both rice (OsPMM) and $B$. distachyon (BdPMM). The cDNA of OsPMM was reported previously [6], whereas that of $B d P M M$ was isolated in this work using RT-PCR (Table 1).

Six different $P M M$ genes were isolated from each of the two bread wheat varieties, Xiaoyan 54 and Chinese Spring (CS). T. urartu, Ae. tauschii and barley were each found to contain two distinct $P M M$ genes, while four different $P M M$ genes were cloned from T. turgi$d u m$. Based on the data on exon and intron pattern, nucleotide and deduced protein identities, chromosomal location, and phylogenetic clustering analysis of genomic coding sequences (see below), the A, B and D genomes were each found to contribute two members to the six $P M M$ genes in bread wheat, which were thus named as TaPMM-A1, B1, D1, A2, B2 and D2, respectively (Table 1). The $P M M-1$ genes in bread wheat and its diploid and tetraploid progenitor species and barley were homoeologous. Likewisely, homoeologous relationship existed among the $P M M-2$ genes from these species.

The intron and exon patterns of the $P M M$ genes from rice, $B$. distachyon, and wheat and relatives were highly similar. Except for OsPMM and BdPMM, both of which had 11 exons owing to the split of the first exon into two parts, the remaining genes all had 10 exons and 9 introns (Figure 1). Apart from PMM-A2 homoeologs and $H \nu P M M-2$, the remaining Triticeae PMM genes cloned in this work all contained intact ORF. The coding region of $H v P M M-2$ was disrupted by premature stop codon based on analyzing the PCR products amplified from two barley varieties (Betzes, Zaoshou 3) (Table 1, Additional file 1).

Consistent with our earlier study [6], the proteins deduced from the $P M M$ genes of common wheat and progenitor species, barley and $B$. distachyon were more

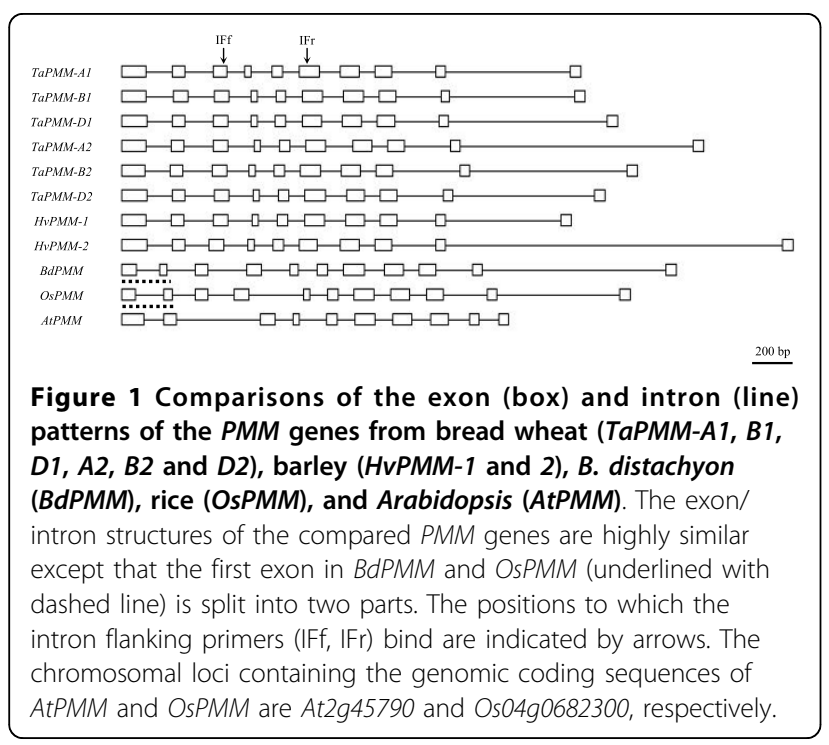

than $50 \%$ identical to the PMMs of human and S. cerevisiae (Additional file 2). The identities among the grass PMMs were generally above 90\%, with BdPMM showing higher identity to its homologs from bread wheat and related Triticeae species than to OsPMM. The identities among the deduced PMM-1 proteins of bread wheat and its diploid and tetraploid ancestors were generally $98 \%$ or higher, with complete identity found among the deduced TaPMM-A1, TuPMM-A1, TtPMM$\mathrm{A} 1$ and TaPMM-B1 proteins. The identities among the deduced PMM-B2 and D2 proteins of bread wheat and its diploid and tetraploid ancestors were generally $97 \%$. By contrast, the identities between the deduced PMM-1 and 2 proteins were comparatively lower, being $95 \%$ between B1 and B2 proteins, and 96\% between D1 and D2 proteins. The deduced PMM-B1 (or B2) proteins of tetraploid and bread wheats were $99 \%$ identical. Interestingly, TaPMM-B2 and TtPMM-B2 displayed unusual amino acid substitutions. The first one, involving the substitution of a broadly conserved glycine residue by alanine, was shared between TaPMM-B2 and TtPMMB2 (Additional file 3). The second one was unique to TaPMM-B2, involving the replacement of a highly conserved arginine residue by cysteine. The four structural and active site motifs (motifs I to IV), identified by analyzing the crystal structure of HsPMM-1 [7], were generally conserved among the compared plant PMMs (Additional file 3).

\section{Determination of $P M M$ copy number and chromosomal locations}

To investigate the copy number of $P M M$ genes, we made use of intron length polymorphisms and designed a pair of intron flanking (IF) primers (Additional file 4), which enabled the amplification of PCR fragments containing introns III to V (Figure 1). By carefully analyzing the products amplified with fluorescently labeled IF primers, six distinct fragments were found for bread wheat (varieties Xiaoyan 54 and CS), and their size equaled to that calculated from the six cloned TaPMM genomic sequences in all cases (Additional file 5). Using the same strategy, two PMM fragments were found for T. urartu (accessions DV877 and IE29-1), Ae. tauschii (accessions AS67 and AS91) and barley (Betzes), respectively, and for all three species, the size of the amplified fragments corresponded exactly to the one deduced from the cloned $P M M$ members (Additional file 5). Four fragments were amplified from $T$. turgidum (Langdon, LDN), whose size again showed specific correspondence to that derived from each of the four cloned TtPMM members (Additional file 5). Finally, a single fragment was amplified from $B$. distachyon $(\mathrm{Bd} 21)$ and its size agreed with the one calculated from the cloned $B d P M M$ genomic sequence (Additional file 5). 
The copy number of $P M M$ genes in an additional set of materials (containing 12 diploid and 9 tetraploid Triticeae species) was also investigated by fragment analysis using the IF primers (see above). The results showed that the diploid Triticeae species carrying the $\mathrm{A}^{\mathrm{m}} \mathrm{A}^{\mathrm{m}}$, CC, MM, NN, RR, SS, $S^{\mathrm{b}} S^{\mathrm{b}}, S^{\mathrm{l}} S^{\mathrm{l}}, \mathrm{S}^{\mathrm{s}} S^{\mathrm{s}}, \mathrm{S}^{\mathrm{sh}} \mathrm{S}^{\mathrm{sh}}, \mathrm{S}^{\mathrm{t}} S^{\mathrm{t}}$ or UU genomes generally had two different PMM fragments, whereas the tetraploid Triticeae species containing the AAGG, DDCC, DDMM, DDNN or UUMM genomes generally possessed four PMM specific fragments (Additional file 6).

The fluorescently labeled IF primers were further employed for investigating the chromosomal locations of wheat and barley PMM members by PCR amplifications. The fragments derived from $P M M-A 1, B 1$ and $D 1$ of bread wheat were not amplified from the NT lines lacking 2A, 2B and 2D chromosomes, respectively (Additional file 7), indicating that TaPMM-1 homoeologs were located on group 2 chromosomes. This finding was confirmed by the fragment analysis data obtained with LDN substitution lines (Additional file 7). The fragments derived from $P M M-A 2$ and $D 2$ members of bread wheat were not amplified from the NT lines lacking 4A and 4D chromosomes, respectively (Additional file 7). Moreover, the fragment from TtPMM-B2 was absent in the LDN substitution line lacking the $4 \mathrm{~B}$ chromosome (Additional file 7). Together, these results indicated that TaPMM-2 homoeologs were located on group 4 chromosomes. Using a similar strategy, the two barley $P M M$ genes were mapped to the $2 \mathrm{H}$ and $4 \mathrm{H}$ chromosomes, respectively (Additional file 8), which are homoeologous to wheat groups 2 and 4 chromosomes, respectively $[27,28]$.

The finding of six PMM genes located on groups 2 and 4 chromosomes in bread wheat by this work is consistent with the data generated in the wheat expressed sequence tag (EST) mapping project http://wheat.pw. usda.gov/NSF/progress_ mapping.html. The EST BE489906, a 421 bp cDNA exhibiting higher than $95 \%$ nucleotide sequence identity to the 5' half of the mRNAs of the six bread wheat PMM genes, has been used as a probe to hybridize with the genomic DNA samples of CS and associated NT lines digested with the restriction enzyme EcoRI. The hybridization yields 11 positive bands, which are mapped to groups 2 or 4 chromosomes. Our bioinformatic analysis suggests the presence of three to five EcoRI sites in the genomic ORF of bread wheat PMM genes, with the last EcoRI site located in the 8th exon (Additional file 9). Because the first seven exons give rise to the 5' half of PMM mRNAs upon post transcriptional processing, the DNA blot hybridization with BE489906 probe is expected to show about 11 to 12 hybridizing bands from six TaPMM gene members. The hybridization with another
PMM EST probe (BE591860) yields approximately seven positive bands, which are mapped mainly to groups 2 or 4 chromosomes. Consequently, it is suggested that the number of homoeologous $P M M$ genes in bread wheat is likely to be around six. However, we can not exclude the existence of additional and divergent $P M M$ copies or fragments in bread wheat genome, because they may not be amplified by our PCR strategy (owing to mutations in the primer binding sites), or be distinguishable from one or more of the six completely sequenced copies during fragment analysis (because of the lack of difference in intron length).

\section{Duplication of $P M M$ in diploid Triticeae species}

The foregoing experiments indicated that there existed two $P M M$ genes (PMM-1, PMM-2) in diploid Triticeae species, and a single $P M M$ gene in either $B$. distachyon or rice. These findings raised an important question on how and when the two PMM gene members in diploid Triticeae species were evolved. To investigate this question, phylogenetic analysis was conducted using the genomic DNA sequences of $P M M$ genes. Two distinct clades, one composed of Triticeae PMM-2 homoeologs and the other of the $P M M-1$ homoeologs from common wheat and progenitors, were consistently found in the phylogenetic trees constructed using different tree building methods (Figure 2). HvPMM-1, BdPMM and OsPMM fell outside of the two clades, with $H v P M M-1$ showing a closer association with both clades than $B d P M M$ and OsPMM (Figure 2). These observations, plus the established synteny between barley chromosome 2 (harboring $H v P M M-1$ ) and rice chromosome 4 (on which OsPMM resides) [27-29], indicated that the Triticeae $P M M-1$ genes were most likely the orthologs of $B d P M M$ and OsPMM, and that the Triticeae PMM-2 member may be derived from $P M M-1$ through duplication. Trees with topology highly similar to that displayed in Figure 2 were also obtained when the deduced amino acid sequences of the PMM genes were used for phylogenetic analysis, but they could not reveal the phylogenetic relationships of $P M M-A 2$ homoeologs to other $P M M$ genes because TaPMM-A2, TtPMM-A2 and TuPMM-A2 could not yield intact proteins upon conceptual translation (Table 1 ).

To find the approximate timing at which the duplication of Triticeae PMM occurred, we first calculated the number of substitutions per synonymous site for the grass $P M M$ genes characterized in this work. The values of synonymous substitutions calculated with PMM-1 genes were generally lower compared to those obtained with PMM-2 members (Table 2). This prompted us to calculate the molecular clocks for grass $P M M-1$ and 2 genes, respectively. Based on the averaged synonymous substitutions between OsPMM 


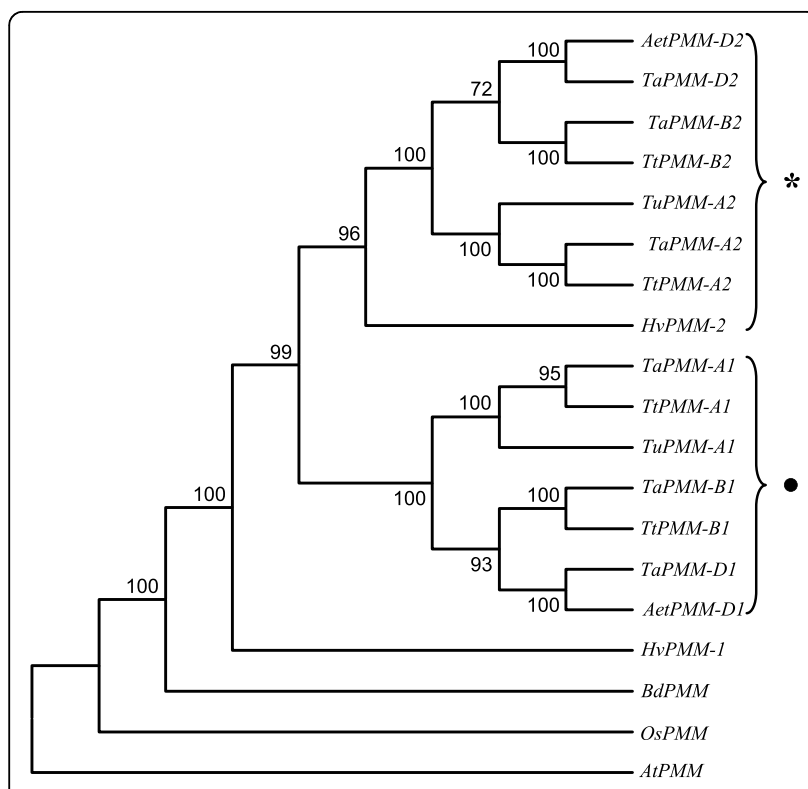

Figure 2 Phylogenetic analysis of $P M M$ genes. The $P M M$ sequences from bread wheat (TaPMM-A1, B1, D1, A2, B2, and D2), $T$. turgidum (TtPMM-A1, B1, A2, and B2), T. urartu (TuPMM-A1 and A2), Ae. tauschii (AetPMM-D1 and D2), barley (HVPMM-1 and 2), B. distachyon (BdPMM), rice (OsPMM, chromosomal locus Os04g0682300), and Arabidopsis (AtPMM, chromosomal locus At2g45790) were used for this analysis. The filled dot and asterisk indicate the two clades composed of Triticeae PMM-1 and 2 homoeologs, respectively. The tree shown was constructed based on an alignment of the nucleotide sequences of PMM genes by neighbor joining method (with $\mathrm{P}$ distance and complete deletion options). Highly similar results were obtained by alternative tree building programs (UPGMA, minimum evolution) (data not shown). The bootstrap values were each estimated using 500 replications. AtPMM was used as an outgroup control.

and wheat $P M M-1$ or 2 genes (Table 2), and assuming that rice and wheat diverged about 60 MYA [22], the average nucleotide substitution rate for $P M M-1$ genes was estimated to be $3.7 \times 10^{-9}$ per site per year, whereas that for $P M M-2$ genes was $4.2 \times 10^{-9}$ per site per year. $B d P M M$ and wheat $P M M-1$ genes diverged about 40.2 \pm 6.6 MYA (Table 3). The divergence time between wheat $P M M-1$ and 2 genes was estimated to be $18.9 \pm 4.0$ or $16.6 \pm 3.6$ MYA, depending on whether the clock rates of $P M M-1$ or 2 genes were used for the calculation (Table 3).

\section{Analysis of evolutionary rate and potential positive selection}

The cDNA sequence of $11 P M M$ genes (including seven $P M M-1$ and four PMM-2 members from bread wheat and its progenitor species) were aligned (Additional file 10 ), and the resultant alignment was used to construct a NJ tree (Additional file 10). The non-synonymous/ synonymous substitution rate ratios $\left(\omega=d_{\mathrm{N}} / d_{\mathrm{S}}\right)$ were calculated for analyzing evolution rate and potential positive selection on amino acid sites by appropriate models (Table 4). The analysis with one-ratio model (M0) produced an averaged $\omega$ value of 0.15 , indicating that purifying selection dominated the evolution of the examined PMM gene members (Table 4). The analysis with two-ratio model revealed that the mean $\omega$ value of $P M M-2$ genes was larger than that of $P M M-1$ members, though this difference was not statistically significant by the likelihood-ratio test (LRT) comparing one-ratio with two-ratio models (Table 4$)$. The analysis with six site specific models, M1a, M2a, M3 $(k=2)$, M3 $(k=3)$, M7 and M8, suggested that more than $90 \%$ of codon sites were under strong purifying selection (with $p$ ranging from 0.91 to 0.99 , Table 4). Two candidate sites (10 and 96) were found to be under positive selection based on naïve empirical Bayes (NEB) posterior probability, one of which (site 10) was significant (Table 4, Additional file 10). However, the positive selection on site 10 was not significant according to Bayes empirical Bayes (BEB) posterior probability, and neither was it supported by LRT (Table 4).

\section{Transcriptional patterns of six TaPMM genes}

Semiquantitative RT-PCR experiments, using member specific primers, were conducted to compare the transcriptional patterns of six PMM genes in Xiaoyan 54. In general, the transcripts of the six $P M M$ members were detectable in both vegetative (root, culm, leaf) and reproductive (immature spikes) organs, with relatively higher transcript levels detected in the seedling and flag leaves (Figure 3 ). The transcript levels of TaPMM-1 members $(A 1, B 1, D 1)$ were generally and relatively higher than those of TaPMM-2 members $(A 2, B 2, D 2)$ (Figure 3). The transcriptional profiles of the three TaPMM-1 genes were basically similar, except that the transcript level of $D 1$ in the immature spikes was much lower relative to those of $A 1$ or $B 1$ (Figure 3). Among the three TaPMM-2 members, $B 2$ and $D 2$ showed a highly similar transcriptional profile (Figure 3). The transcript levels of $A 2$ in the roots, culms and immature spikes were substantially lower than those of $B 2$ and $D 2$ in the same set of organs (Figure 3).

\section{Biochemical activity of TaPMM proteins}

First, yeast complementation assays were carried out to test if the proteins expressed from TaPMM-A1, B1, $D 1, B 2$ or $D 2$ may complement the temperature sensitivity of the sec53-6 mutant of S. cerevisiae. TaPMM$A 2$ was not included because it did not possess an intact ORF (Table 1). From Figure 4, it is clear that the expression of TaPMM-A1, B1, D1 or D2 restored the growth of $\sec 53-6$ cells at 30 or $37^{\circ} \mathrm{C}$, and to a 
Table 2 Relative synonymous substitutions of PMM genes from rice, $B$. distachyon, bread wheat, and barley ${ }^{a}$

\begin{tabular}{lll}
\hline PMM genes compared & $\begin{array}{l}\text { Number of substitutions } \\
\text { per synonymous site (dS) }\end{array}$ & Averaged dS \\
\hline OsPMM/BdPMM & $0.4231 \pm 0.0646$ & \\
OsPMM/HvPMM-1 & $0.4807 \pm 0.0723$ & \\
OsPMM/TaPMM-A1 & $0.4324 \pm 0.0656$ & $0.4385 \pm 0.0669$ (OsPMM/TaPMM1 genes) \\
OsPMM/TaPMM-B1 & $0.4573 \pm 0.0701$ & \\
OsPMM/TaPMM-D1 & $0.4259 \pm 0.0651$ & $0.4997 \pm 0.0763$ (OsPMM/TaPMM2 genes) \\
OsPMM/TaPMM-B2 & $0.5150 \pm 0.0791$ & \\
OsPMM/TaPMM-D2 & $0.4844 \pm 0.0735$ & \\
BdPMM/HvPMM-1 & $0.3449 \pm 0.0542$ & $0.2974 \pm 0.0486$ (BdPMM/TaPMM1 genes) \\
BdPMM/TaPMM-A1 & $0.2884 \pm 0.0471$ & \\
BdPMM/TaPMM-B1 & $0.3121 \pm 0.0508$ & \\
BdPMM/TaPMM-D1 & $0.2918 \pm 0.0479$ & $0.3503 \pm 0.0562$ (BdPMM/TaPMM2 genes) \\
BdPMM/TaPMM-B2 & $0.3647 \pm 0.0583$ & \\
BdPMM/TaPMM-D2 & $0.3358 \pm 0.0541$ & $0.0971 \pm 0.0237$ (HvPMM-1/TaPMM1 genes) \\
HvPMM-1/TaPMM-A1 & $0.0921 \pm 0.0229$ & \\
HvPMM-1/TaPMM-B1 & $0.1126 \pm 0.0261$ & \\
HvPMM-1/TaPMM-D1 & $0.0867 \pm 0.0222$ & \\
HvPMM-1/TaPMM-B2 & $0.1857 \pm 0.0355$ & $0.1826 \pm 0.0351$ (HvPMM-1/TaPMM2 genes) \\
HvPMM-1/TaPMM-D2 & $0.1795 \pm 0.0346$ & \\
TaPMM-B1/TaPMM-B2 & $0.1567 \pm 0.0323$ & $0.1398 \pm 0.0299$ (TaPMM1/TaPMM2 genes) \\
\hline
\end{tabular}

${ }^{a}$ The dS values and their standard deviations were calculated using PMM CDNA coding sequences. TaPMM-A2 was not included in the calculation owing to the occurrence of mutation in its coding region.

similar degree. By contrast, the expression of TaPMMB2 complemented PMM deficiency of sec53-6 only weakly at $30^{\circ} \mathrm{C}$, with no complementation observed at $37^{\circ} \mathrm{C}$ (Figure 4).

Subsequently, TaPMM-A1, B1, B2, D1 and D2 were individually expressed in the bacterial cells, and the resultant recombinant proteins were purified using nickel affinity chromatography (Additional file 11). The recombinant proteins of $\mathrm{A} 1, \mathrm{~B} 2, \mathrm{D} 1$ and $\mathrm{D} 2$ were examined for catalytic activity using mannose-1-phosphate as the substrate. The $\mathrm{B} 1$ recombinant protein was not included in this analysis because its deduced amino acid sequence was identical to that of A1 (Additional file 2). In three independent experiments, B2 did not show detectable catalytic activity. By contrast, the recombinant A1, D1 and D2 proteins were all catalytically active. The average $K_{\mathrm{m}}$ (mM, mannose-1-phosphate) values calculated for recombinant $\mathrm{A} 1, \mathrm{D} 1$ and $\mathrm{D} 2$ proteins were $0.46 \pm 0.02,0.40 \pm 0.02$ and $0.48 \pm 0.02$, respectively.
Temperature-activity profiles of the recombinant PMMs of rice, $B$. distachyon, barley and bread wheat

$O s P M M, B d P M M$ and $H v P M M-1$ were expressed in the bacterial cells, and the resultant recombinant proteins were purified as described above. The main temperature-activity characteristics of the three PMMs and TaPMM-A1, D1 and D2 were compared using $1 \mathrm{mM}$ mannose-1-phosphate as the substrate and at three test temperatures $\left(24,30\right.$ and $\left.37^{\circ} \mathrm{C}\right)$. From Figure 5, it is evident that the activity level of OsPMM was significantly higher at 30 and $37^{\circ} \mathrm{C}$ than at $24^{\circ} \mathrm{C}$. Moreover, increasing the test temperature from 30 and $37^{\circ} \mathrm{C}$ did not decrease OsPMM activity significantly (Figure 5). BdPMM was most active at $30^{\circ} \mathrm{C}$, but its activity level was reduced by nearly $95 \%$ as the temperature increased from 30 to $37^{\circ} \mathrm{C}$ (Figure 5). HvPMM-1 was most active at $24^{\circ} \mathrm{C}$, and its activity level also decreased sharply (by more than 90\%) as the temperature shifted from 30 to $37^{\circ} \mathrm{C}$ (Figure 5). The three bread wheat PMMs exhibited different temperature-activity characteristics.

Table 3 Divergence time estimates for PMM genes

\begin{tabular}{lll}
\hline & $\begin{array}{l}\text { Divergence time } \\
\text { (MYA) }\end{array}$ & Averaged dS value used for the estimation \\
\hline BdPMM vs TaPMM-1 & $40.2 \pm 6.6^{\mathrm{a}}$ & $0.2974 \pm 0.0486$ (BdPMM/TaPMM-1 genes) \\
TaPMM-1 vs TaPMM-2 & $18.9 \pm 4.0^{\mathrm{a}}$ & $0.1398 \pm 0.0299$ (TaPMM-1/TaPMM-2 genes) \\
& $16.6 \pm 3.6^{\mathrm{b}}$ & \\
\hline
\end{tabular}

a Specific molecular clock used for the estimation: $3.7 \times 10^{-9}$ per site per year.

${ }^{\text {b }}$ Specific molecular clock: $4.2 \times 10^{-9}$ per site per year. 
Table 4 Maximum-likelihood analysis of PMM-1 and 2 genes and detection of codon sites under positive selection

\begin{tabular}{|c|c|c|c|c|c|c|c|c|}
\hline \multirow[b]{2}{*}{ Model } & \multirow[b]{2}{*}{$P$} & \multirow[b]{2}{*}{ Likelihood } & \multirow[b]{2}{*}{ Parameter estimate ${ }^{a}$} & \multirow[b]{2}{*}{ NEB ${ }^{b}$} & \multirow[b]{2}{*}{$\mathrm{BEB}^{\mathrm{b}}$} & \multicolumn{3}{|c|}{ Likelihood ratio test (LRT) } \\
\hline & & & & & & $2 \Delta l$ & df & $P$ value \\
\hline$\overline{\mathrm{MO} \text { (one ratio) }}$ & 1 & -1433.52 & $\omega=0.155$ & $\mathrm{NA}$ & NA & & & \\
\hline Two ratio & 2 & -1433.09 & $\begin{array}{l}\omega_{\text {PMM-1 }}=0.114 \\
\omega_{\text {PMM-2 }}=0.186\end{array}$ & NA & NA & $\begin{array}{l}0.4223 \text { (two ratio } \\
\text { versus one ratio) }\end{array}$ & 1 & 0.5158 \\
\hline M1a: nearly neutral & 1 & -1430.84 & $\begin{array}{l}p_{0}=0.917 ; p_{1}=0.083 \\
\omega_{0}=0.076 ; \omega_{1}=1.000\end{array}$ & NA & NA & & & \\
\hline M2a: positive selection & 3 & -1429.69 & $\begin{array}{l}p_{0}=0.989 ; p_{1}=0.000 ; \\
p_{2}=0.011 ; \\
\omega_{0}=0.119 ; \omega_{1}=1.000 ; \\
\omega_{2}=4.902\end{array}$ & $\begin{array}{l}10 \mathrm{~N}(0.999 *) \\
96 \mathrm{H}(0.793)\end{array}$ & $10 \mathrm{~N}(0.867) ; 96 \mathrm{H}(0.680)$ & $\begin{array}{l}2.2947 \text { (M2a versus } \\
\text { M1a) }\end{array}$ & 2 & 0.3175 \\
\hline M3: discrete $(k=2)$ & 3 & -1429.69 & $\begin{array}{l}p_{0}=0.989 ; p_{1}=0.011 \\
\omega_{0}=0.119 ; \omega_{1}=4.901\end{array}$ & $\begin{array}{l}10 \mathrm{~N}\left(0.999^{*}\right) \\
96 \mathrm{H}(0.793)\end{array}$ & None & & & \\
\hline M3: discrete $(k=3)$ & 5 & -1429.69 & $\begin{array}{l}p_{0}=0.933 ; p_{1}=0.056 ; \\
p_{2}=0.011 ; \\
\omega_{0}=0.119 ; \omega_{1}=0.120 ; \\
\omega_{2}=4.902\end{array}$ & $\begin{array}{l}10 \mathrm{~N}\left(0.999^{*}\right) \\
96 \mathrm{H}(0.793)\end{array}$ & None & $\begin{array}{l}7.6562(\mathrm{M} 3 \\
\text { versus M0) }\end{array}$ & 4 & 0.1050 \\
\hline M7: beta & 2 & -1431.48 & $p=0.0489 ; q=0.241$ & NA & NA & NA & & \\
\hline M8: beta and $\omega$ & 4 & -1429.70 & $\begin{array}{l}p_{0}=0.989 ; p=13.583 \\
q=99.000 ; \\
p_{1}=0.011 ; \omega=4.909\end{array}$ & $\begin{array}{l}10 \mathrm{~N}\left(0.999^{*}\right) \\
96 \mathrm{H}(0.786)\end{array}$ & $10 \mathrm{~N}(0.944) ; 96 \mathrm{H}(0.778)$ & $\begin{array}{l}3.5539(\mathrm{M} 7 \\
\text { versus M8) }\end{array}$ & 2 & 0.1692 \\
\hline
\end{tabular}

a $\omega$ values are $d_{\mathrm{N}} / d_{\mathrm{S}}$ ratios. $p_{0}, p_{1}$ and $p_{2}$ indicate the proportion of sites in categories 1,2 or 3 .

${ }^{b}$ The codon sites $(10 \mathrm{~N}, 96 \mathrm{H})$ were numbered based on TaPMM-D1 CDNA (Additional file 10). Asterisk denotes statistical significance level at or above 0.95. NEB, naïve empirical bayes; $B E B$, Bayes empirical bayes; NA, not applicable.

TaPMM-A1 was less active than BdPMM and HvPMM1 at 24 and $30^{\circ} \mathrm{C}$, but its activity level was substantially higher than those of BdPMM and HvPMM-1 at $37^{\circ} \mathrm{C}$, owing to a $51 \%$ increase of its activity as the temperature changed from 30 to $37^{\circ} \mathrm{C}$ (Figure 5). TaPMM-D2, although less active than BdPMM and HvPMM-1 at 24 and $30^{\circ} \mathrm{C}$, displayed substantially higher activity levels than BdPMM and HvPMM-1 at $37^{\circ} \mathrm{C}$, because the change of test temperature from 30 to $37^{\circ} \mathrm{C}$ did not reduce TaPMM-D2 activity as strongly as that occurred to BdPMM and HvPMM-1 (Figure 5). The activity level of TaPMM-D1 was lower than those of BdPMM and HvPMM-1 but higher than those of TaPMM-A1 and $\mathrm{D} 2$ at $24^{\circ} \mathrm{C}$ (Figure 5). However, TaPMM-D1 was highly active at $30^{\circ} \mathrm{C}$, with an activity level statistically comparable to that of OsPMM (Figure 5). The shift of assay temperature from 30 to $37^{\circ} \mathrm{C}$ reduced the activity of TaPMM-D1 by about $40 \%$, but the scale of this reduction was much lower compared to that observed for BdPMM, HvPMM-1 or TaPMM-D2.

\section{Discussion}

\section{PMM genes and chromosomal loci in Triticeae species}

Through the molecular cloning experiments in this work, the following suggestions may be made regarding $P M M$ genes and chromosome loci in Triticeae species. First, there exist two distinct $P M M$ gene members $(P M M-1$ and 2$)$ in the progenitor diploid genomes (i.e., A, B and D) of bread wheat. There are four and six $P M M$ genes (including both active and inactive members) in tetraploid and hexaploid wheats, respectively. Second, in bread wheat and its diploid and tetraploid progenitors, the loci containing $P M M-1$ or 2 genes are located on homoeologous groups 2 and 4 chromosomes, respectively. Third, two PMM genes (HvPMM-1 and 2) exist in diploid barley. The loci harboring $H v P M M-1$ or 2 are located on the $2 \mathrm{H}$ and $4 \mathrm{H}$ chromosomes, respectively. Finally, judging from the fragment analysis data of $P M M$ genes described in Additional file 6 , it is probable that the basic organization of $P M M$ gene family, as defined for the A, B, D and $\mathrm{H}$ genomes (e.g., two distinct members contained in two separate chromosomal loci), is conserved in the diploid Triticeae species possessing $\mathrm{A}^{\mathrm{m}} \mathrm{A}^{\mathrm{m}}, \mathrm{CC}, \mathrm{MM}, \mathrm{NN}, \mathrm{RR}, \mathrm{SS}, \mathrm{S}^{\mathrm{b}} \mathrm{S}^{\mathrm{b}}$, $S^{\mathrm{l}} S^{1}, S^{\mathrm{s}} S^{\mathrm{s}}, S^{\text {sh }} S^{\text {sh }}, S^{\mathrm{t}} S^{\mathrm{t}}$ or UU genomes. However, further work is needed to verify if in the 12 Triticeae genomes the two PMM genes may also be located on homoeologous group 2 and 4 chromosomes.

The existence of two PMM genes in diploid Triticeae species contrasts with the finding of a single $P M M$ gene for Arabidopsis, rice and B. distachyon [[6,12], this work]. A search of recently accumulated genomic data deposited in the phytozome website (http://www.phytozome.net) reveals that Medicago truncatula, Vitis vinifera, Sorghum bicolor and Zea mays each possess a single $P M M$ gene. However, both Glycine max and Populus trichocarpa harbor two PMM copies in their genomes (http://www.phytozome.net). Two functional $P M M$ copies have also been found present in several mammals (e.g., human, mouse and rat) [30-32]. 


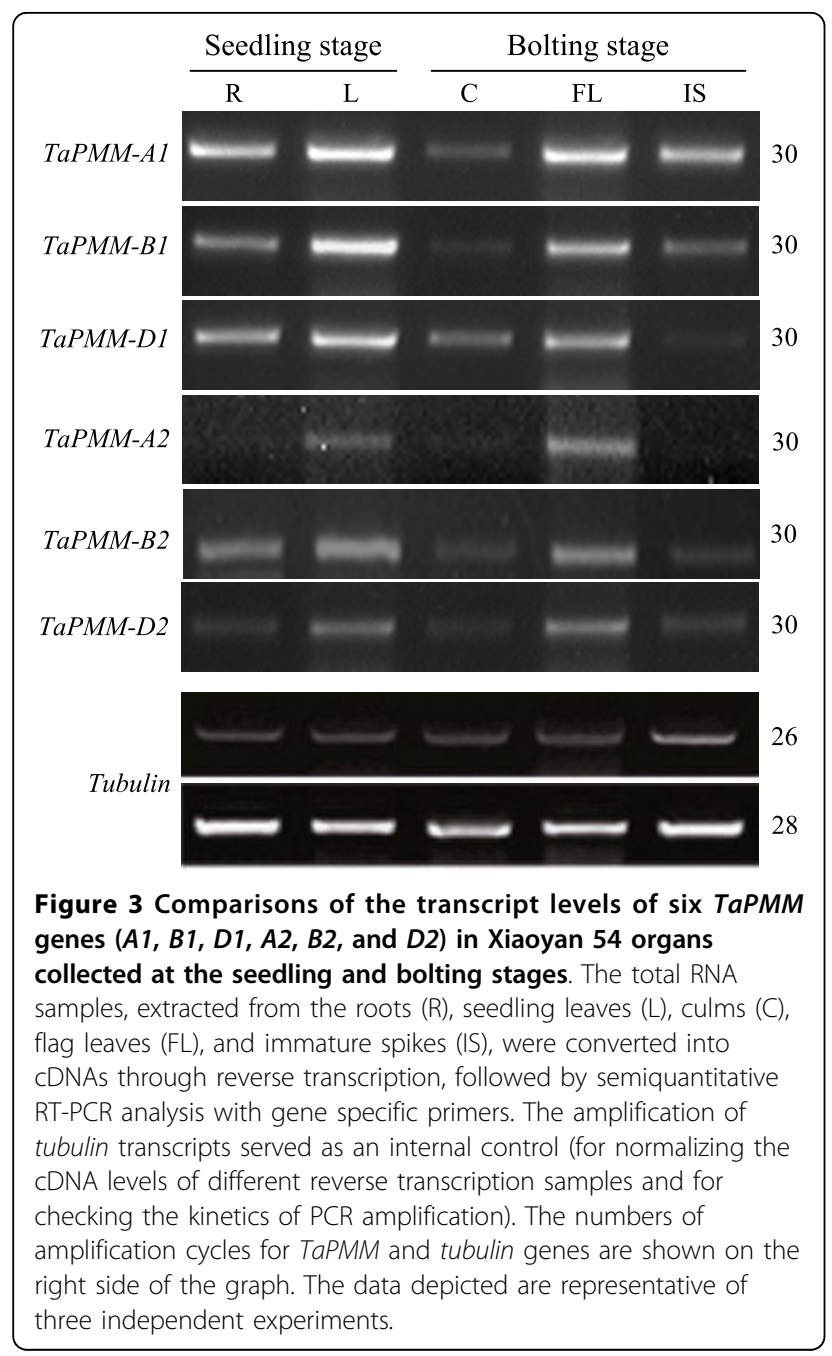

\section{Biochemically active PMM members in bread wheat and its progenitors}

From the presence of intact ORF, the results of yeast complementation experiments, and the data of biochemical assays using recombinant proteins, we deduce that bread wheat expresses four biochemically active PMMs, TaPMM-A1, B1, D1 and D2. The primary structure and basic biochemical function of the four PMMs are similar to their orthologs in human, S. cerevisiae and Arabidopsis. In contrast to TaPMM-A1, B1, D1 and D2, TaPMM-B2 is probably not active in vivo because it did not complement PMM deficiency of yeast sec53-6 cells efficiently, and was not catalytically competent in the in vitro biochemical assay. The lack of detectable biochemical activity by TaPMM-B2 correlates with the presence of unusual amino acid substitutions in its deduced protein (Additional file 3). Further work is needed to determine the specific amino acid change(s) responsible for decreasing the biochemical activity of TaPMM-B2.

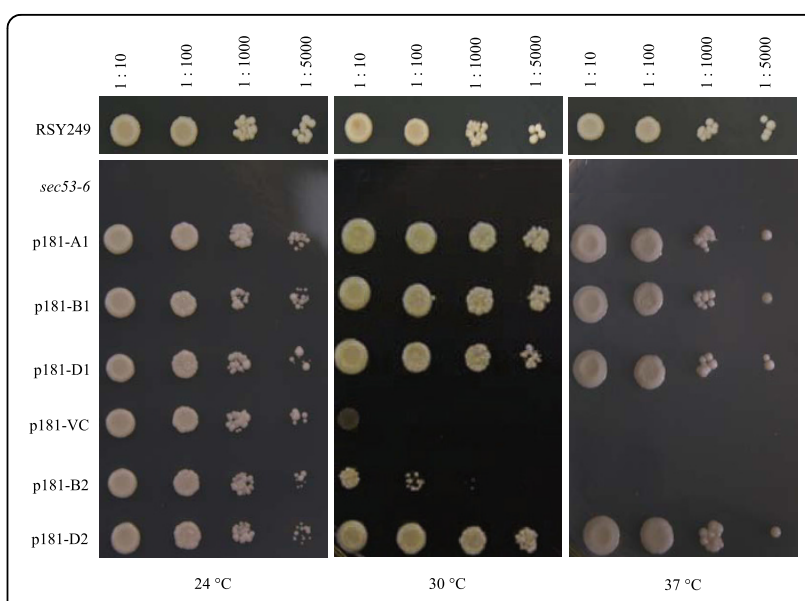

Figure 4 Yeast complementation analysis of TaPMM genes. Five yeast constructs, harboring the CDNA of TaPMM-A1 (p181-A1), B1 (p181-B1), D1 (p181-D1), B2 (p181-B2) or D2 (p181-D2), were prepared using the expression vector p181AINE (containing a Leu2 selection marker). These constructs, together with the empty vector control (p181-VC), were transformed into the sec53-6 strain of S. cerevisiae, which does not grow at elevated temperatures $\left(30^{\circ} \mathrm{C}\right.$ or above) because of temperature sensitive mutation in the native PMM. The six recombinant strains, sec53-6, and RSY249 (the wild type progenitor of sec53-6) were serially diluted and spotted onto the medium lacking leucine, followed by incubation at three test temperatures $\left(24,30\right.$ or $\left.37^{\circ} \mathrm{C}\right)$, The data shown are reproducible in three independent experiments.

Owing to the possession of identical amino acid sequences (Additional file 2), it is likely that TuPMMA1 (in $T$. urartu) behaves like TaPMM-A1, and AetPMM-D1 and D2 of Ae. tauschii may act like

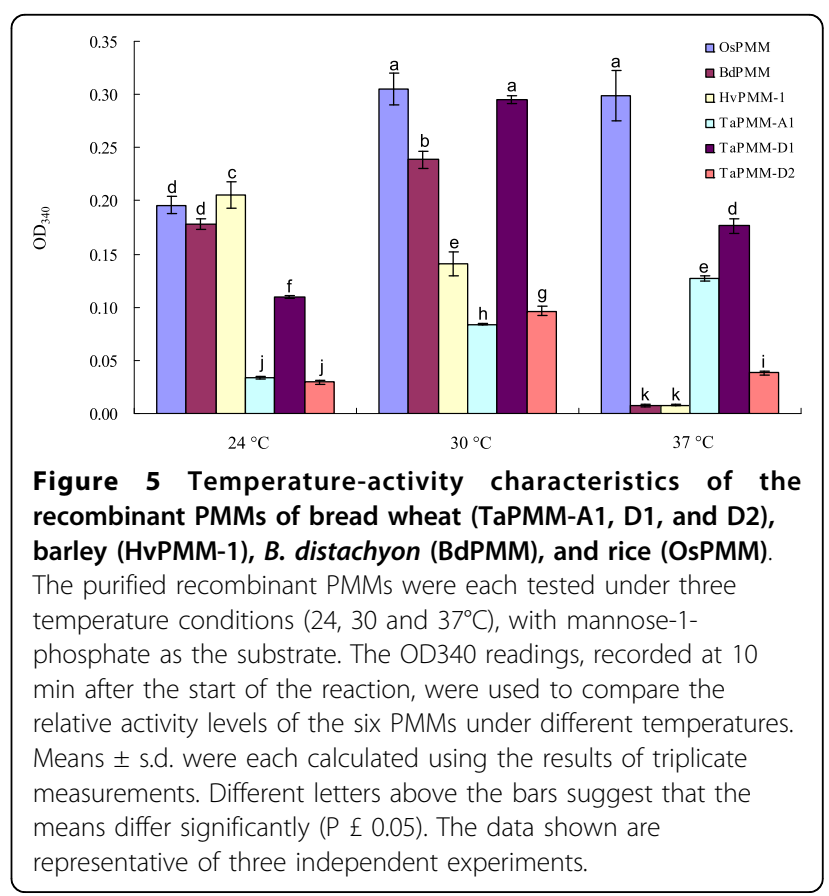


TaPMM-D1 and D2, respectively. Contrary to the above scenario, it is not possible to deduce the biochemical activity of TtPMM-B1 and B2 based on the data gathered for TaPMM-B1 and B2, because complete amino acid sequence identity did not exist between the two B1 or B2 members (Additional file 2).

\section{Main features of PMM evolution in diploid and polyploid Triticeae species}

Despite its vital importance in eukaryotes, the molecular evolution of $P M M$ has not been investigated in higher plants previously, and has been studied only recently in animals. Several investigations suggest that the presence of two functional PMM copies in human and murine cells may be caused by a gene duplication event that occurred 75 to 110 MYA [30,32-34]. From the data presented in this work, the main features in the evolution of $P M M$ genes in diploid and polyploid Triticeae species may be summarized below. First, a major event in PMM evolution in the diploid Triticeae species carrying AA, $\mathrm{A}^{\mathrm{m}} \mathrm{A}^{\mathrm{m}}, \mathrm{BB}, \mathrm{CC}, \mathrm{DD}, \mathrm{HH}, \mathrm{MM}, \mathrm{NN}, \mathrm{RR}, \mathrm{SS}, \mathrm{S}^{\mathrm{b}} \mathrm{S}^{\mathrm{b}}, \mathrm{S}^{\mathrm{l}} \mathrm{S}^{\mathrm{l}}$, $S^{s} S^{s}, S^{\text {sh }} S^{\text {sh }}, S^{t} S^{t}$ or UU genomes is the duplication of $P M M$. This duplication event gave rise to two different $P M M$ genes, $P M M-1$ and 2, located on groups 2 and 4 chromosomes, respectively. Out of the two $P M M$ genes in diploid Triticeae species, $P M M-1$ is likely more ancestral. This possibility is mainly supported by 1 ) the phylogenetic tree shown in Figure 2,2) the existence of a single $P M M$ gene in rice, and 3 ) the established syntenic relationship between Triticeae group 2 chromosomes (on which $P M M-1$ homoeologs are located) and rice chromosome 4 (on which OsPMM resides) [27-29]. Second, the $P M M$ duplication, as discussed above, occurred after the divergence between $B$. distachyon and wheat, but before the radiation of diploid Triticeae genomes. This is supported by not only the presence of two different $P M M$ gene members in many diploid Triticeae genomes examined in this work, but also the estimated divergence time between TaPMM-1 and TaPMM-2 genes (Table 3). The two estimates, whether $16.6 \pm 3.6$ or $18.9 \pm 4.0 \mathrm{MY}$, are both much larger than the divergence time between wheat and barley (about $11 \mathrm{MY}$ ) reported in past studies [19-22]. But they are substantially smaller than the divergence time between $B$. distachyon and wheat (35 to $37.8 \mathrm{MY}$ ) calculated by previous investigations $[35,36]$. Third, substantial differences exist in the evolutionary patterns of $P M M-1$ and 2 genes. $P M M-1$ genes generally had intact ORF, their transcript levels in the vegetative and reproductive organs were comparatively higher (Figure 3), and their protein products were all biochemically active (Figure $5)$. By contrast, multiple types of defects occurred to $P M M-2$ members. The $P M M-A 2$ copies in bread wheat and its diploid and tetraploid progenitors and $H v P M M-$
2 in barley possessed mutated ORF (Table 1). TaPMM$B 2$ encoded a protein with undetectable biochemical activity (Figure 4). The recombinant protein of TaPMM-D2 was significantly less active than that of the product of TaPMM-D1 (Figure 5). Moreover, the three $P M M-2$ members in bread wheat all exhibited lower transcript levels relative to their $P M M-1$ paralogs (Figure 3). Fourth, the differences of $P M M-1$ and 2 genes established at the diploid level (i.e., in the $\mathrm{A}^{\mathrm{u}}$ or $\mathrm{D}$ genomes) are basically retained in polyploid wheats. Thus, $P M M-A 1$ is active in diploid, tetraploid and hexaploid levels whereas the ORF of PMM-A2 is disrupted at all three ploidy levels. The two $P M M$ genes encoded in $\mathrm{D}$ genome are all active in both Ae. tauschii and bread wheat. In contrast to the PMM genes in A and D genomes, the origin of the contrasting biochemical features of the two $\mathrm{B}$ genome PMM members in bread wheat is unclear at present, because the absence of a diploid species containing the $\mathrm{B}$ genome made it difficult to study the evolution of $P M M-B 1$ and $B 2$ members at the diploid level. Finally, from the data described in Additional file 6, the duplicated $P M M$ genes in the G, C, N, $\mathrm{M}$ and $\mathrm{U}$ genomes are also likely retained in the tetraploid species possessing AAGG, DDCC, DDMM, DDNN or UUMM genomes, although further work is needed to study the PMM genes in these species in more detail.

Because $P M M-1$ and 2 genes were located on groups 2 and 4 chromosomes, respectively, in wheat and progenitors and barley, the duplication event that led to the formation of two PMM copies in the ancestral Triticeae species must have occurred interchromosomally. Strong evidence for the occurrence of interchromosomal duplications in wheat genome evolution has been obtained in recent years [37-39]. Importantly, it has been suggested that these duplications are largely conserved across different Triticeae species $[39,40]$. However, it is still not well understood how these events might be accomplished in Triticeae genomes. Thus, the PMM duplication reported here may serve as a useful model for studying the molecular mechanisms underlying the interchromosomal duplications in Triticeae in the future.

The average nucleotide substitution rates of grass $P M M-1$ or 2 genes estimated based on the 60 MY divergence time between rice and wheat by this work are both lower than the commonly adopted mutation rate $\left(6.5 \times 10^{-9}\right.$ per site per year) for grass genes [41-44] This may not be unusual because evolutionary rates frequently differ among different grass genes [45]. For example, the mutation rates of ten randomly selected grass genes have been found to vary from 4.1 to $7.1 \times$ $10^{-9}$ per site per year [45]. Furthermore, we estimated that the divergence time between $B d P M M$ and wheat 
PMM-1 genes was about 40.2 $\pm 6.6 \mathrm{MY}$ (Table 3) using the average nucleotide substitution rate calculated for grass $P M M-1$ genes. This estimate is comparable to the previously reported timeline (35 to $37.8 \mathrm{MY}$ ) for the divergence of the two species $[35,36]$.

\section{Possible mechanisms involved in the evolution of $P M M-1$ and 2 genes}

Past studies have suggested several fates in the evolution of duplicated genes [46-48]. Neofunctionalization leads to the acquisition of new function by one copy, whereas subfunctionalization renders the progenitor and the duplicated copy acquiring non-overlapping but complementary expression patterns. Non-functionalization results in pseudogenization of one of the duplicates. In barley, the duplicate copy of HvHox2 (encoding a homeodomain-leucine zipper transcription factor) acquired a new function in controlling spikelet fertility [49]. In rice, evidence for subfunctionalization has been obtained for two C-class MADS box genes (OSMADS3 and OSMADS58) [50]. The evolutionary process of duplicated genes may be divided into two stages [51]. During the early stage, the duplicates generally evolve under purifying selection, with a phase of relaxed selective constraint immediately after the duplication [51,52]. During the later stage, the great majority of the duplicates become non-functional pseudogenes that are no longer expressed, with only a few of them being involved in neofunctionalization or subfunctionalization [51-53].

From the data in Table 4 and the main evolutionary features of $P M M-1$ and 2 genes discussed above, we suggest that 1) purifying selection, but not positive selection, may have dominated the evolution of PMM gene family in wheat and relatives, and 2) despite the prevalence of purifying selection, the function of $P M M$ 2 copies is not as strongly maintained as that of PMM-1 members. The first point is consistent with the findings that the vast majority of duplicated genes in cellular organisms experience purifying selection [51,52], even though some of them are in the process of becoming pseudogenes [54]. Owing to purifying selection, the $P M M-1$ genes are generally and relatively stable. By contrast, TaPMM-A2 is close to becoming a non-functional pseudogene, because its ORF was mutated and its transcript level was decreased relative to $P M M-1$ genes (Figure 3). This scenario may also apply to $P M M-A 2$ copies in the diploid and tetraploid progenitors of bread wheat and $H v P M M-2$ in barley although further work is needed to check if the transcript levels of these members may be lowered than those of PMM-1 genes. TaPMM-B2 and D2, although possessing intact ORF, also show signs of degenerative evolution, because their transcript levels were lower than corresponding $P M M-1$ members, and the PMM enzyme activity of their recombinant proteins was either undetectable or reduced (Figure 4 and 5). The degeneration of $P M M-2$ genes and the comparatively high mean evolutionary rate of these members indicate the occurrence of relaxed purifying selection in the evolution of PMM gene family in wheat and relatives, which may have affected $P M M-2$ copies more strongly than $P M M-1$ paralogs. However, further work is needed to verify this hypothesis.

In contrast to the degenerative evolution of the duplicated PMM-2 copies in diploid Triticeae species, the two mammalian PMM members, products of a duplication event occurred before the radiation of mammals (i.e., 75 to $110 \mathrm{MYA}$ ), all encode highly active enzymes [29-33]. However, unlike PMM2 whose mutation leads to hypoglycosylation of cellular proteins and severe disease $[9,12]$, the deletion of PMM1 in mouse does not cause obvious abnormalities in either growth or development under normal conditions [33]. Moreover, despite their overlapping expression profiles, PMM1 does not compensate for the functional loss of PMM2 $[32,33]$. These findings have led to the suggestion that PMM1 may have diverged from PMM2 in physiological function [33]. This possibility has been confirmed with the recent discovery that PMM1 but not PMM2 acts as a glucose-1,6-bisphosphatase in the brain tissues [55]. Clearly, the unique $P M M$ duplication event in Triticeae plants revealed in this work differs from the one in mammals in multiple aspects including the timing of the event, the evolutionary fates of $P M M$ members after the duplication, and possibly the main mechanism involved in the evolution. The evolutionary knowledge generated in this work increases our understanding of $P M M$ evolution in eukaryotes, and may be useful for future studies of $P M M$ evolution in additional plant species such as G. max and P. trichocarpa, both of which have been found to contain two PMM genes (see above).

\section{The main active $P M M$ isozymes in bread wheat tissues}

Among the four biochemically active TaPMMs, functional similarity may be limited to only TaPMM-A1 and B1 because their deduced proteins were identical, and the transcriptional patterns of their coding genes were very similar (Figure 3). By contrast, functional differences are likely to exist among A1(B1), D1 and D2 members because of dissimilarities in their deduced amino acid sequences and transcriptional patterns. For further analysis of the physiological function of PMM genes in bread wheat, it is necessary to find out the main active PMM isozymes in vivo. Considering the fundamental importance of PMM in the temperature adaptability of eukaryotes $[1,12]$, the differences in the temperature-activity profiles of the four enzymatically active TaPMMs are of particular interest. From the data shown in Figure 5, it is suggested that 
TaPMM-D1 may be highly active in a wider range of temperatures (from 24 to $37^{\circ} \mathrm{C}$ ). The activity of TaPMM-A1 is less than that of TaPMM-D1, but it is unique in exhibiting the highest activity at $37^{\circ} \mathrm{C}$ (although this activity level was still below that of TaPMM-D1 at $37^{\circ} \mathrm{C}$ ). The activity of TaPMM-D2 is generally lower than that of TaPMM-D1 and $\mathrm{A} 1$, especially at $37^{\circ} \mathrm{C}$ (Figure 5 ). This finding and the observation that the transcript levels of TaPMM-D2 were considerably lower than those of TaPMM-A1, B1 and D1 in multiple organs (Figure 3 ) indicate that TaPMM-A1, B1 and D1 are likely to be the main active PMM isozymes in bread wheat tissues. Moreover, judging from Figure 3, at least two main PMM isozymes are expressed in each of the five organs (root, seedling leaf, culm, flag leaf, and developing spike) examined in this work.

As displayed in Figure 5, rice, a tropical cereal and adaptable to both tropical and temperate regions [56], possesses a PMM showing very high activity levels at elevated test temperatures $\left(30\right.$ and $37^{\circ} \mathrm{C}$ ). By contrast, $B$. distachyon, barley and bread wheat, originated from temperate regions [57-59], have the PMMs exhibiting relatively high activity levels at 24 or $30^{\circ} \mathrm{C}$ (Figure 5). A general decrease in the activities of the PMMs of $B$. distachyon, barley and bread wheat at $37^{\circ} \mathrm{C}$ seems to correlate with the temperate origin of these species. However, compared with BdPMM and HvPMM-1, at $37^{\circ} \mathrm{C}$, the magnitude of activity decrease was much smaller for TaPMM-D1 and D2, and the activity of TaPMM-A1 even increased relative to its performance at 24 and $30^{\circ}$ C. This indicates that bread wheat PMM isozymes may be generally more stable than their counterparts in $B$. distachyon and barley at elevated test temperatures (such as $37^{\circ} \mathrm{C}$ ), which correlates well with the wide temperature adaptability of the bread wheat crop $[13,14]$.

\section{Conclusion}

This work has generated new information on PMM genes and their evolution in bread wheat and related Triticeae species. The main active PMM isozymes (e.g., TaPMM-A1, B1 and D1) in bread wheat tissues are revealed. The three isozymes may be more tolerant to elevated temperatures than their counterparts in barley and $B$. distachyon. The insights gained in this work have broadened the understanding of PMM evolution in eukaryotic organisms. The resources produced here may aid future investigations of the physiological function of this important gene in the temperature adaptability of bread wheat.

\section{Methods}

Plant materials, yeast strains and oligonucleotide primers The wheat and barley varieties and the T. urartu, T. turgidum ssp. dicoccoides, Ae. tauschii and B. distachyon genotypes used for cloning PMM genes are listed in
Additional file 1. The NT lines of CS, the D genome substitution lines in the tetraploid wheat variety LDN background, and the barley chromosome addition lines in CS background, employed for mapping the chromosomal locations of PMM genes, are also listed in Additional file 1 . The growth of wheat and related Triticeae species was accomplished as described previously [6]. $B$. distachyon was cultured in the greenhouse under a constant temperature $\left(23^{\circ} \mathrm{C}\right)$ and with a $16 \mathrm{~h}$ light $/ 8 \mathrm{~h}$ dark photoperiod. Two S. cerevisiae strains, sec53-6 (MAT $a$, sec53-6, leu2-3, -112, ura3-52) and its wild type progenitor RSY249 used for the yeast complementation experiment, were described previously [6]. The oligonucleotide primers used in this work are all listed in Additional file 4. The general molecular methods for handling nucleic acid and protein samples, PCR amplification, DNA cloning, and protein expression in bacterial cells were adopted from Sambrook and Russell [60]. High fidelity Taq DNA polymerases, LA-Taq (TaKaRa, China) and Advantage 2 Polymerase Mix (Clontech, USA), were used in PCR amplifications. The accuracy of the yeast or bacterial expression constructs prepared in this work was all confirmed by DNA sequencing.

\section{Cloning of PMM CDNA and genomic DNA sequences}

Total RNA samples were prepared from the desired leaf materials using RNeasy plant mini kit (Qiagen, Germany), and were converted into cDNAs using Moloney Murine leukemia virus (M-MLV) reverse transcriptase (Promega, USA). Public nucleotide and protein data banks were searched using the cDNA and deduced amino acid sequence of rice $P M M(O s P M M)$ [6], leading to the finding of the ESTs derived from wheat and barley PMM genes. By analyzing the obtained ESTs, the oligonucleotide primers permitting the amplifications of full length cDNA and genomic DNA sequences of the PMM genes from bread wheat and related Triticeae species (T. urartu, T. turgidum, Ae. tauschii, barley) were developed (Additional file 4). With these primers and the reverse transcription products described above, the $P M M$ cDNAs from bread wheat and relatives were amplified by RT-PCR, cloned and sequenced. The PMM cDNA of $B$. distachyon was cloned using a similar strategy, except that the development of the oligonucleotide primers specific for $B d P M M$ was facilitated by the genome sequence of Bd21 (http://www.phytozome.net/brachy.php). Genomic DNA samples were extracted from the relevant leaf materials as detailed previously [61], and used for isolating the genomic coding sequences of the PMM genes of bread wheat and related Triticeae species and $B$. distachyon with the same sets of primers employed for cDNA cloning.

During the above experiments, at least 70 positive PCR clones derived from three separate cloning 
experiments were sequenced for each of the plant species examined in this work. This ensured the identification of the cDNA and genomic DNA sequences corresponding to different $P M M$ genes. The final nucleotide sequences for the cDNA and genomic DNA coding regions of a given $P M M$ gene were each constructed from the sequencing information of at least three independent clones. The nucleotide sequences of the PMM genes cloned in this work have all been submitted to GenBank. The accession numbers are listed in Additional file 12 .

\section{Investigation of PMM copy number and chromosomal location}

The genomic PCR products amplified with the IF primers (Additional file 4, Figure 1) from Xiaoyan 54 were confirmed to be derived from $P M M$ genes by cloning and sequencing. The amplified fragments differed in size, which was thus useful for distinguishing the different $P M M$ genes and estimating the copy number of $P M M$ in bread wheat, its Triticeae relatives, and $B$. distachyon. The forward IF primer was labeled with D4 fluorescence by a commercial company (TaKaRa, China), allowing the separation and identification of PCR products via capillary electrophoresis $(\mathrm{CE})$ and fragment analysis in the CEQ/GeXP Genetics Analysis System (GAS) (Beckman, USA). The preparation of PCR products for $\mathrm{CE}$ and the subsequent fragment analysis in CEQ/GeXP GAS were conducted following the supplier's instructions. Using the same strategy, PMM copy numbers in the Triticeae species carrying the diploid $\mathrm{A}^{\mathrm{m}} \mathrm{A}^{\mathrm{m}}, \mathrm{CC}, \mathrm{MM}, \mathrm{NN}, \mathrm{RR}, \mathrm{SS}, \mathrm{S}^{\mathrm{b}} S^{\mathrm{b}}, S^{\mathrm{l}} S^{\mathrm{l}}, S^{\mathrm{s}} S^{\mathrm{s}}, S^{\text {sh }} S^{\text {sh }}, S^{\mathrm{t}} S^{\mathrm{t}}$ or UU genomes, or the tetraploid AAGG, DDCC, DDMM, DDNN or UUMM genomes (Additional file 6), were also investigated.

For investigating $P M M$ chromosomal location, the $P M M$ gene specific fragments, amplified from CS, the different NT lines of CS, LDN, and the D genome substitution lines in LDN background, were separated using $\mathrm{CE}$ and differentiated by fragment analysis. The IF primers and fragment analysis were also used for mapping the chromosomal locations of two barley $P M M$ genes (HvPMM-1 and 2). In this case, the DNA samples extracted from the barley variety Betzes and its derivative chromosome addition lines in CS background were utilized as templates for genomic PCR amplifications.

\section{Bioinformatic, phylogenetic and evolutionary analysis of PMM}

Bioinformatic investigations of cloned PMM genes were carried out using the softwares installed in public websites, including EBI (http://www.ebi.ac.uk/Tools/), ExPASy (http://www.expasy.ch/tools/) and NCBI (http:// www.ncbi.nlm.nih.gov/). Full length genomic DNA sequences of $P M M$ genes were aligned using the Clustalw2 program (EBI website). The resulted alignment was used for constructing phylogenetic trees by MEGA4 [62]. The number of substitutions per synonymous site (dS) was calculated as described previously [63]. The average nucleotide substitution rates for $P M M-1$ and 2 genes were estimated by the formula $k=d S / 2 t$ [64], assuming a divergence time of $60 \mathrm{MY}$ between rice and wheat [22]. The obtained rates were then used to estimate the timing of PMM duplication in wheat.

To investigate the potential mechanisms behind the evolution of PMM genes in bread wheat and its progenitor Triticeae species, two complementary evolutionary tests (one for difference in the evolutionary rates of $P M M-1$ and 2 genes, and the other for the codon sites under positive selection) were carried out by the CODEML program implemented in the PAML package [65]. The NJ tree, constructed using the cDNA sequence of 11 active $P M M-1$ and 2 genes, was employed for these tests. The one-ratio and two-ratio models [66,67] were used for investigating evolutionary rate, whereas the site specific models M1a, M2a, M3 $(k=2)$, M3 $(k=$ $3)$, M7 and M8 [68,69] were deployed for testing potential diversifying selection at individual codon sites. Statistical analysis of the evolutionary data was conducted as described previously, with the confidence level set at or above $0.95[70,71]$.

\section{Semiquantitative RT-PCR}

The seeds of Xiaoyan 54 were germinated for $48 \mathrm{~h}$ at $25^{\circ} \mathrm{C}$, followed by 4 weeks vernalization treatment at $4^{\circ}$ C. The vernalized seedlings were then grown in the greenhouse as described above. The root and seedling leaf samples were collected after two weeks growth in the greenhouse. The stem, flag leaf, and immature spike samples were collected at the bolting stage (after 5 weeks growth in the greenhouse). The isolation of total RNA samples from the collected materials and cDNA synthesis were conducted as described above. Semiquantitative RT-PCR analysis of the relative transcript levels of 6 TaPMM genes in different wheat organs was performed using gene specific primers (Additional file 4), and following the method detailed previously [72]. The amplification of wheat tubulin transcripts served as an internal control, and the reproducibility of the transcriptional patterns revealed was verified in three independent experiments.

\section{Yeast complementation}

The complementation assay was conducted as described previously [6]. Briefly, five complementation constructs (p181-A1, B1, D1, B2 and D2) were prepared by cloning the cDNAs of TaPMM-A1, B1, D1, B2 and D2 individually into the yeast expression vector p181AINE. The 
oligonucleotide primers used for amplifying TaPMM cDNAs during the cloning are listed in Additional file 4. The five constructs, together with the empty vector control (p181-VC), were individually introduced into the sec53-6 strain whose endogenous $P M M$ harbors a temperature sensitive mutation [1]. The recombinant strains were serially diluted and plated onto agar medium, followed by incubation at three temperatures $(24,30$ and $37^{\circ} \mathrm{C}$ ). As controls, sec53-6 and its wild type progenitor RSY249 were also included in the growth assays. Successful complementation by TaPMM expression was indicated by restoring the growth of sec53-6 cells at elevated temperatures $\left(30\right.$ and $\left.37^{\circ} \mathrm{C}\right)$. The complementation assay was repeated three times to verify the reproducibility of the data obtained.

\section{Biochemical analysis of recombinant PMMs}

The $P M M$ cDNAs from bread wheat (TaPMM-A1, B1, $D 1, B 2$ and D2), barley (HvPMM-1), B. distachyon $(B d P M M)$ and rice (OsPMM) were individually cloned into the bacterial expression vector pET-30a (Novagen, USA), in order to express recombinant PMM proteins with a C-terminal histidine tag. The oligonucleotide primers used for amplifying PMM cDNAs during preparing the bacterial expression constructs are provided in Additional file 4. The induction of $P M M$ cDNA expression in the bacterial cells and the purification of histidine tagged PMMs through metal chelate affinity chromatography were accomplished as described previously [6]. The purified PMMs were characterized using $10 \%$ SDS-PAGE, and were confirmed to be the desired histidine tagged proteins by protein blotting using an anti-histidine antibody (Roche Diagnostic GmbH, Germany) [6].

The kinetic properties of the purified recombinant TaPMM-A1, B2, D1 and D2 were investigated using mannose-1-phosphate as the substrate, and following the method detailed in our earlier work [6]. The assay was repeated three times for each of the four recombinant TaPMMs. The resultant data were used to calculate average $K_{\mathrm{m}}$ values. The temperature-activity characteristics of OsPMM, BdPMM, HvPMM-1, and TaPMM-A1, D1 and D2 were examined using $1 \mathrm{mmol} /$ L mannose-1-phosphate as the substrate, with the assays conducted at three different temperatures $(24,30$ and $37^{\circ} \mathrm{C}$ ). The $\mathrm{OD}_{340}$ readings were collected at $10 \mathrm{~min}$ after the start of the enzyme assays. At this time point, the reactions catalyzed by the six recombinant PMMs were in the linear phase. The assay was repeated three times per recombinant PMM per test temperature, with each assay consisting of three technical replicates. The $\mathrm{OD}_{340}$ readings obtained were statistically analyzed using the software SPSS 10 for comparing the relative activity levels of the six recombinant PMMs.

\section{Additional material}

Additional file 1: Plant materials. The materials were used for PMM gene cloning and chromosomal localization experiments.

Additional file 2: Amino acid sequence identities. The PMM proteins under comparison were from wheat and related species, yeast $(S$. cerevisiae, ScPMM), human (HsPMM1 and 2), Arabidopsis (AtPMM), rice (OsPMM) and B. distachyon (BdPMM).

Additional file 3: Alignment of the deduced amino acid sequences of the PMMs from wheat and related Triticeae species, $B$. distachyon (BdPMM), rice (OsPMM), and human (HsPMM1 and 2). The four structural motifs required for PMM catalysis are boxed. The replacement of a broadly conserved arginine residue by cysteine (marked in red) was found in TaPMM-B2, whereas the substitution of a highly conserved glycine residue by alanine (written in blue) was observed in both TaPMM-B2 and TtPMM-B2. Asterisks indicate identical residues. The symbols ":" and "." represent conserved and semi-conserved substitutions, respectively. The Swiss-Prot accession numbers for OsPMM, HsPMM1 and HsPMM2 are Q7XPW5, Q92871 and 015305, respectively.

Additional file 4: Oligonucleotide primers used in this work. Additional file 5: Investigation of PMM copy numbers in bread wheat and related Triticeae species (T. urartu, Ae. tauschii, $H$. vulgare, $T$. turgidum ssp. durum) and $B$. distachyon by fragment analysis. PMM gene specific peaks are indicated by arrows. The minor peaks labeled by asterisks are caused by DNA size standards. The scale on the horizontal axis indicates fragment size (number of nucleotides), which was determined using the DNA size standards co-separated with the PCR products. The specific genotypes used in this analysis are provided in the brackets. The data shown are representative of five independent experiments.

Additional file 6: Estimation of PMM copy numbers in the diploid and tetraploid species possessing additional Triticeae genomes.

Additional file 7: Chromosomal assignment of PMM genes in hexaploid and tetraploid wheats. The fragments specific for individual PMM gene members were amplified by PCR, followed by separation via capillary electrophoresis. The templates for PCR were prepared from Chinese Spring (CS), the nulli-tetrasomic (NT) lines of CS, the durum wheat variety Langdon (LDN), and the D genome substitution lines in LDN background. The PMM genes represented by the major peaks (fragments) are shown. The minor peaks labeled by asterisks are due to DNA size markers. The scale on the horizontal axis indicates fragment size. (a) Compared to the presence of all six PMM specific fragments in $C S$, the fragments representing $P M M-A 1, B 1, D 1, A 2$ or $D 2$ genes were specifically absent from the NT lines lacking chromosomes 2A (N2AT2D), 2B (N2BT2D), 2D (N2DT2A), 4A (N4AT4D) or 4D (N4DT4A). The six PMM specific fragments were all amplified in the NT lines lacking other groups (i.e., 1, 3, 5, 6 and 7) of chromosomes (data not shown). (b) The presence of four PMM specific fragments in LDN. Note that the fragments representing $P M M-A 1, B 1$ or $B 2$ genes were not amplified from the substitution lines 2D(2A) (lacking 2A chromosome), 2D(2B) (lacking 2B chromosome) or $4 \mathrm{D}(4 \mathrm{~B})$ (lacking $4 \mathrm{~B}$ chromosome). The fragment representing $P M M-D 1$ was amplified from $2 \mathrm{D}(2 \mathrm{~A})$ and $2 \mathrm{D}(2 \mathrm{~B})$ owing to the presence of $2 \mathrm{D}$ chromosome in the two lines. Similarly, the fragment representing PMM-D2 was amplifiable from $4 \mathrm{D}(4 \mathrm{~B})$ due to the presence of $4 D$ chromosome in this line. The PMM-A1, B1, $A 2$ and $B 2$ fragments were all amplifiable in the other substitution lines in which $2 A, 2 B, 4 A$ and $4 B$ chromosomes are not involved in the substitution by $D$ genome chromosomes (data not shown). The data displayed are typical of five independent sets of experiments.

Additional file 8: Chromosomal locations of barley PMM genes (HvPMM-1 and 2). The genomic DNA samples, extracted from the bread wheat variety Chinese Spring (CS), barley variety Betzes, and barley chromosome addition lines in CS background, were used for PCR amplifications with the nucleotide primers capable of recognizing PMM genes from Triticeae species. The peaks in blue represent PCR fragments amplified from specific bread wheat or barley PMM genes. The six PMM genes in CS are abbreviated as $A 1, B 1, D 1, A 2, B 2$ and $D 2$, respectively. HVPMM-1 and 2 were found in the two addition lines containing barley 
$2 \mathrm{H}(\mathrm{CS}-2 \mathrm{H})$ and $4 \mathrm{H}(\mathrm{CS}-4 \mathrm{H})$ chromosomes, respectively. The fragment pattern of the remaining addition lines was identical to that of CS (data not shown). The peaks marked by asterisks were caused by DNA size standards. The data shown are typical of three independent experiments. Additional file 9: Distribution of multiple EcoRI sites in the genomic ORFs of six bread wheat PMM genes. The locations of the sites are calculated in relation to the start codon ATG (with the A nucleotide as 1). The exons are represented by boxes.

Additional file 10: The cDNA sequence alignment and phylogenetic genetic tree of $P M M$ genes used for evolutionary rate and positive selection analysis. (a) Multiple alignment of the CDNA sequences of 11 active PMM genes from bread wheat and its progenitor species. The sequences are each presented in codon format. The stop codon is not included in the alignment. Codon site 10 (numbered according to TaPMM-D1), which was significantly positively selected based on based on NEB posterior probability, is labeled in purple. (b) The phylogenetic tree used for evolutionary analysis. This tree was constructed using neighbor joining program with complete deletion and the Kimura-2 nucleotide substitution model. The bootstrap value was estimated using 500 replications.

Additional file 11: SDS-PAGE analysis of recombinant TaPMM-A1, $B 1, D 1, B 2$, and D2 proteins purified using metal chelate affinity chromatography. The size of protein molecular mass (kD) standards is shown on the left side of the graph.

Additional file 12: GenBank accession numbers of the PMM genes isolated in this work.

\section{Acknowledgements}

We thank our colleagues (listed under Additional files 1 and 6) for supplying the germplasm materials used in this work. In addition, we are grateful to Drs Mingsheng Chen and Jinfeng Chen (Institute of Genetics and Developmental Biology, Chinese Academy of Sciences, China) for valuable suggestions on phylogenetic and evolutionary analysis, and Professor Rudi Appels (Centre for Comparative Genomics, Murdoch University, Australia) for constructive advice on manuscript preparation. This work was supported by grants from the Ministry of Science and Technology of China (grants 2009CB1 18300 and 2006AA100102) and the National Natural Science Foundation of China (grants 30771306 and 30821061).

\section{Author details}

'The State Key Laboratory of Plant Cell and Chromosome Engineering, Institute of Genetics and Developmental Biology, Chinese Academy of Sciences, Beijing 100101, PR China. ${ }^{2}$ Life Science School, Nantong University, Nantong 226019, PR China. ${ }^{3}$ Graduate University of Chinese Academy of Sciences, Beijing 100049, PR China.

\section{Authors' contributions}

CY participated in experimental design, cloned PMM genes, determined PMM copy number, and conducted RT-PCR, yeast complementation, protein purification and biochemical experiments. YL, BL, LH, JC, WQ, SL, GW, SB and $\mathrm{HQ}$ contributed resources, reagents and greenhouse facilities to experiments. $X \mathrm{~L}$ and $\mathrm{HY}$ performed evolutionary analysis. QS, LC and $\mathrm{AZ}$ took part in designing and supervising the study. DW designed and supervised the study and participated in drafting the manuscript. All authors have read and approved the final manuscript.

Received: 10 May 2010 Accepted: 5 October 2010 Published: 5 October 2010

\section{References}

1. Kepes F, Schekman R: The yeast SEC53 gene encodes phosphomannomutase. J Biol Chem 1988, 263:9155-9161.

2. Seifert GJ: Nucleotide sugar inter-conversions and cell wall biosynthesis: how to bring the inside to the outside. Curr Opin Plant Biol 2004, 7:277-284
3. Lerouge P, Cabanes-Macheteau M, Rayon C, Fischette-Lainé AC, Gomord V, Faye L: N-glycoprotein biosynthesis in plants: recent developments and future trends. Plant Mol Biol 1998, 38:31-48.

4. Spiro RG: Protein glycosylation: nature, distribution, enzymatic formation, and disease implications of glycopeptide bonds. Glycobiology 2002, 12:43R-56R.

5. Wheeler GL, Jones MA, Smirnoff N: The biosynthetic pathway of vitamin C in higher plants. Nature 1998, 393:365-369.

6. Qian W, Yu C, Qin H, Liu X, Zhang A, Johansen IE, Wang D: Molecular and functional analysis of phosphomannomutase (PMM) from higher plants and genetic evidence for the involvement of PMM in ascorbic acid biosynthesis in Arabidopsis and Nicotiana benthamiana. Plant J 2007, 49:399-413.

7. Silvaggi NR, Zhang C, Lu Z, Dai J, Dunaway-Mariano D, Allen KN: The X-ray crystal structures of human alpha-phosphomannomutase 1 reveal the structural basis of congenital disorder of glycosylation type 1a. J Biol Chem 2006, 281:14918-14926.

8. Matthijs G, Schollen E, Pardon E, Veiga-Da-Cunha M, Jaeken J, Cassiman Jر, Van Schaftingen E: Mutations in PMM2, a phosphomannomutase gene on chromosome 16p13, in carbohydrate-deficient glycoprotein type I syndrome (Jaeken syndrome). Nat Genet 1997, 16:88-92.

9. Matthijs G, Schollen E, Van Schaftingen E, Cassiman JJ, Jaeken J: Lack of homozygotes for the most frequent disease allele in carbohydratedeficient glycoprotein syndrome type 1A. Am J Hum Genet 1998, 62:542-550.

10. Freeze $\mathrm{HH}$, Aebi M: Molecular basis of carbohydrate-deficient glycoprotein syndromes type I with normal phosphomannomutase activity. Biochim Biophys Acta 1999, 1455:167-178.

11. Aebi $\mathrm{M}$, Hennet $\mathrm{T}$ : Congenital disorders of glycosylation: genetic model systems lead the way. Trends Cell Biol 2001, 11:136-141.

12. Hoeberichts FA, Vaeck E, Kiddle G, Coppens E, van de Cotte B, Adamantidis A, Ormenese S, Foyer $C H$, Zabeau M, Inzé D, Périlleux C, Van Breusegem F, Vuylsteke M: A temperature-sensitive mutation in the Arabidopsis thaliana phosphomannomutase gene disrupts protein glycosylation and triggers cell death. J Biol Chem 2008, 283:5708-5718.

13. Worland AJ, Snape JW: Genetic basic of worldwide wheat varietal improvement. In The World Wheat Book: A History of Wheat Breeding. Edited by: Bonjean AP, Angus WJ. Paris: Lavoisier Publishing; 2001:59-100.

14. Lillemo M, Ginkel MV, Trethowan RM, Hernandez E, Crossa J: Differential adaptation of CIMMYT bread wheat to global high temperature environments. Crop Sci 2005, 45:2443-2453.

15. Knüpffer $\mathrm{H}$ : Triticeae genetic resources in ex situ genebank collections. In Genetics and Genomics of the Triticeae. Edited by: Feuillet C, Muehlbauer GJ. Dordrecht/Heidelberg/London/New York: Springer; 2009:31-80.

16. Qi L, Friebe B, Zhang P, Gill BS: Homoeologous recombination, chromosome engineering and crop improvement. Chromosome Res 2007, 15:3-19.

17. Feldman M, Lupton FGH, Miller TE: Wheats. In Evolution of Crops. Edited by: Smartt J, Simmonds NW. London: Longman Scientific; , 2 1995:184-192.

18. Luo MC, Yang ZL, You FM, Kawahara T, Waines JG, Dvorak J: The structure of wild and domesticated emmer wheat populations, gene flow between them, and the site of emmer domestication. Theor Appl Genet 2007, 114:947-959.

19. Huang S, Sirikhachornkit A, Faris JD, Su X, Gill BS, Haselkorn R, Gornicki P: Phylogenetic analysis of the acetyl-CoA carboxylase and 3phosphoglycerate kinase loci in wheat and other grasses. Plant Mol Biol 2002, 48:805-820.

20. Huang S, Sirikhachornkit A, Su X, Faris J, Gill B, Haselkorn R, Gornicki P: Genes encoding plastid acetyl-CoA carboxylase and 3-phosphoglycerate kinase of the Triticum/Aegilops complex and the evolutionary history of polyploid wheat. Proc Natl Acad Sci USA 2002, 99:8133-8138.

21. Dvorak J, Akhunov ED: Tempos of gene locus deletions and duplications and their relationship to recombination rate during diploid and polyploid evolution in the Aegilops-Triticum alliance. Genetics 2005, 171:323-332.

22. Chalupska D, Lee HY, Faris JD, Evrard A, Chalhoub B, Haselkorn R, Gornicki P: Acc homoeoloci and the evolution of wheat genomes. Proc Natl Acad Sci USA 2008, 105:9691-9696.

23. Griffiths S, Sharp R, Foote TN, Bertin I, Wanous M, Reader S, Colas I, Moore G: Molecular characterization of Ph1 as a major chromosome pairing locus in polyploid wheat. Nature 2006, 439:749-752. 
24. Spielmeyer W, Singh RP, McFadden $H$, Wellings CR, Huerta-Espino J, Kong $X$, Appels R, Lagudah ES: Fine scale genetic and physical mapping using interstitial deletion mutants of $L$ r34/Yr18: a disease resistance locus effective against multiple pathogens in wheat. Theor App/ Genet 2008, 116:481-490

25. Turner A, Beales J, Faure S, Dunford RP, Laurie DA: The pseudo-response regulator Ppd-H1 provides adaptation to photoperiod in barley. Science 2005, 310:1031-1034.

26. Nair SK, Wang $N$, Turuspekov $Y$, Pourkheirandish $M$, Sinsuwongwat $S$, Chen G, Sameri M, Tagiri A, Honda I, Watanabe Y, Kanamori H, Wicker T, Stein N, Nagamura Y, Matsumoto T, Komatsuda T: Cleistogamous flowering in barley arises from the suppression of microRNA-guided HvAP2 mRNA cleavage. Proc Natl Acad Sci USA 2010, 107:490-495.

27. Gale MD, Devos KM: Comparative genetics in the grasses. Proc Natl Acad Sci USA 1998, 95:1971-1974.

28. Cho S, Garvin DF, Muehlbauer GJ: Transcriptome analysis and physical mapping of barley genes in wheat-barley chromosome addition lines. Genetics 2006, 172:1277-1285

29. Conley EJ, Nduati V, Gonzalez-Hernandez JL, Mesfin A, Trudeau-Spanjers M Chao S, Lazo GR, Hummel DD, Anderson OD, Qi LL, Gill BS, Echalier B, Linkiewicz AM, Dubcovsky J, Akhunov ED, Dvorák J, Peng JH, Lapitan NL, Pathan MS, Nguyen HT, Ma XF, Miftahudin, Gustafson JP, Greene RA, Sorrells ME, Hossain KG, Kalavacharla V, Kianian SF, Sidhu D, Dilbirligi M, Gill KS, Choi DW, Fenton RD, Close TJ, McGuire PE, Qualset CO, Anderson JA: A 2600-locus chromosome bin map of wheat homoeologous group 2 reveals interstitial gene-rich islands and colinearity with rice. Genetics 2004, 168:625-637.

30. Schollen E, Pardon E, Heykants L, Renard J, Doggett NA, Callen DF, Cassiman JJ, Matthijs G: Comparative analysis of the phosphomannomutase genes $P M M 1, P M M 2$ and $P M M 2 \psi$ the sequence variation in the processed pseudogene is a reflection of the mutations found in the functional gene. Hum Mol Genet 1998, 7:157-164.

31. Pirard M, Achouri Y, Collet JF, Schollen E, Matthijs G, Van Schaftingen E: Kinetic properties and tissular distribution of mammalian phosphomannomutase isozymes. Biochem J 1999, 339:201-207.

32. Heykants L, Schollen E, Grünewald S, Matthijs G: Identification and localization of two mouse phosphomannomutase genes, Pmm1 and Pmm2. Gene 2001, 270:53-59.

33. Thiel C, Lübke T, Matthijs G, von Figura K, Körner C: Targeted disruption of the mouse phosphomannomutase 2 gene causes early embryonic lethality. Mol Cell Biol 2006, 26:5615-5620.

34. Cromphout K, Vleugels W, Heykants L, Schollen E, Keldermans L, Sciot R, D'Hooge R, De Deyn PP, von Figura K, Hartmann D, Körner C, Matthijs G: The normal phenotype of Pmm1-deficient mice suggests that Pmm1 is not essential for normal mouse development. Mol Cell Biol 2006 , 26:5621-5635

35. Bossolini E, Wicker T, Knobel PA, Keller B: Comparison of orthologous loci from small grass genomes Brachypodium and rice: implications for wheat genomics and grass genome annotation. Plant J 2007, 49:704-717.

36. Huo N, Vogel JP, Lazo GR, You FM, Ma Y, McMahon S, Dvorak J, Anderson OD, Luo MC, Gu YQ: Structural characterization of Brachypodium genome and its syntenic relationship with rice and wheat. Plant Mol Biol 2009, 70:47-61.

37. Li W, Gill BS: The colinearity of the Sh2/A1 orthologous region in rice, sorghum and maize is interrupted and accompanied by genome expansion in the Triticeae. Genetics 2002, 160:1153-1162.

38. Akhunov ED, Akhunova AR, Dvorak J: Mechanisms and rates of birth and death of dispersed duplicated genes during the evolution of a multigene family in diploid and tetraploid wheats. Mol Biol Evol 2007, 24:539-550.

39. Choulet F, Wicker T, Rustenholz C, Paux E, Salse J, Leroy P, Schlub S, Le Paslier MC, Magdelenat G, Gonthier C, Couloux A, Budak H, Breen J, Pumphrey M, Liu S, Kong X, Jia J, Gut M, Brunel D, Anderson JA, Gill BS, Appels R, Keller B, Feuillet C: Megabase level sequencing reveals contrasted organization and evolution patterns of the wheat gene and transposable element spaces. Plant Cell 2010 [http://www.plantcell.org/cgi/ doi/10.1105/tpc.110.074187].

40. Salse J, Abrouk M, Bolot S, Guilhot N, Courcelle E, Faraut T, Waugh R, Close TJ, Messing J, Feuillet C: Reconstruction of monocotyledonous proto-chromosomes reveals faster evolution in plants than in animals. Proc Natl Acad Sci USA 2009, 106:14908-14913.
41. Gaut BS, Morton BR, McCaig BC, Clegg MT: Substitution rate comparisons between grasses and palms: synonymous rate differences at the nuclear gene Adh parallel rate differences at the plastid gene $r b c L$. Proc Natl Acad Sci USA 1996, 93:10274-10279.

42. Wicker T, Yahiaoui N, Guyot R, Schlagenhauf E, Liu ZD, Dubcovsky J, Keller B: Rapid genome divergence at orthologous low molecular weight glutenin loci of the $A$ and $A^{\mathrm{m}}$ genomes of wheat. Plant Cell 2003, 15:1186-1197.

43. Ma J, Bennetzen JL: Recombination, rearrangement, reshuffling, and divergence in a centromeric region of rice. Proc Natl Acad Sci USA 2006, 103:383-388.

44. Salse J, Chagué V, Bolot S, Magdelenat G, Huneau C, Pont C, Belcram H, Couloux A, Gardais S, Evrard A, Segurens B, Charles M, Ravel C, Samain S, Charmet $G$, Boudet N, Chalhoub B: New insights into the origin of the B genome of hexaploid wheat: evolutionary relationships at the SPA genomic region with the $\mathrm{S}$ genome of the diploid relative Aegilops speltoides. BMC Genomics 2008, 9:555.

45. Sandve SR, Rudi H, Asp T, Rognli OA: Tracking the evolution of a cold stress associated gene family in cold tolerant grasses. BMC Evol Biol 2008, $8: 245$.

46. Ohno S: Evolution by Gene Duplication. Berlin: Springer-Verlag 1970.

47. Force A, Lynch M, Pickett FB, Amores A, Yan YL, Postlethwait J: Preservation of duplicate genes by complementary, degenerative mutations. Genetics 1999, 151:1531-1545.

48. Taylor JS, Raes J: Duplication and divergence: the evolution of new genes and old ideas. Annu Rev Genet 2004, 38:615-643.

49. Sakuma S, Pourkheirandish M, Matsumoto T, Koba T, Komatsuda T: Duplication of a well-conserved homeodomain-leucine zipper transcription factor gene in barley generates a copy with more specific functions. Funct Integr Genomics 2010, 10:123-133.

50. Yamaguchi T, Lee DY, Miyao A, Hirochika H, An G, Hirano HY: Functional diversification of the two C-class MADS box genes OSMADS3 and OSMADS58 in Oryza sativa. Plant Cell 2006, 18:15-28.

51. Kondrashov FA, Rogozin IB, Wolf YI, Koonin EV: Selection in the evolution of gene duplication. Genome Biol 2002, 3:research0008.1-0008.9

52. Lynch M, Conery JS: The evolutionary fate and consequences of duplicate genes. Science 2000, 290:1151-1155.

53. Zhang J: Evolution by gene duplication: an update. Trends Ecol Evol 2003, 18:292-298.

54. Waters ER, Nguyen SL, Eskandar R, Behan J, Sanders-Reed Z: The recent evolution of a pseudogene: diversity and divergence of a mitochondrialocalized small heat shock protein in Arabidopsis thaliana. Genome 2008, 51:177-186.

55. Veiga-da-Cunha M, Vleugels W, Maliekal P, Matthijs G, Schaftingen EV: Mammalian phosphomannomutase PMM1 is the brain IMP-sensitive glucose-1,6-bisphosphatase. J Biol Chem 2008, 283:33988-33993.

56. Kovach MJ, Sweeney MT, McCouch SR: New insights into the history of rice domestication. Trends Genet 2007, 23:578-587.

57. Nilan RA, Ullrich SE: Barley: taxonomy, origin, distribution, production, genetics, and breeding. In Barley chemistry and technology. Edited by: MacGregor AW, Bhatty RS. St. Paul, MN: American Association of Cereal Chemists; 1993:1-5.

58. Badr A, Müller K, Schäfer-Pregl R, El Rabey H, Effgen S, Ibrahim HH, Pozzi C, Rohde W, Salamini F: On the origin and domestication history of barley (Hordeum vulgare). Mol Biol Evol 2000, 17:499-510.

59. Draper J, Mur LA, Jenkins G, Ghosh-Biswas GC, Bablak P, Hasterok R, Routledge AP: Brachypodium distachyon. A new model system for functional genomics in grasses. Plant Physiol 2001, 127:1539-1555.

60. Sambrook J, Russell RW: Molecular Cloning: A Laboratory Manual. NY: Cold Spring Harbor Laboratory Press 2001.

61. Saghai-Maroof MA, Soliman KM, Jorgensen RA, Allard RW: Ribosomal DNA spacer-length polymorphisms in barley: Mendelian inheritance, chromosomal location, and population dynamics. Proc Natl Acad Sci USA 1984, 81:8014-8018.

62. Tamura K, Dudley J, Nei M, Kumar S: MEGA4: Molecular evolutionary genetics analysis (MEGA) software version 4.0. Mol Biol Evol 2007, 24:1596-1599.

63. Yang Z, Nielsen R: Estimating synonymous and non-synonymous substitution rates under realistic evolutionary models. Mol Biol Evol 2000, 17:32-43. 
64. Sanderson MJ: Estimating rate and time in molecular phylogenies: beyond the molecular clock? In Molecular systematics of plants II: DNA sequencing. Edited by: Soltis DE, Soltis PS, Doyle JJ. Boston/Dordrecht/ London: Kluwer; 1998:242-264.

65. Yang Z: PAML 4: phylogenetic analysis by maximum likelihood. Mol Biol Evol 2007, 24:1586-1591.

66. Yang Z, Nielsen R: Codon-substitution models for detecting molecular adaptation at individual sites along specific lineages. Mol Biol Evol 2002, 19:908-917.

67. Zhang J, Nielsen R, Yang Z: Evaluation of an improved branch-site likelihood method for detecting positive selection at the molecular level. Mol Biol Evol 2005, 22:2472-2479.

68. Yang Z: Likelihood and Bayes estimation of ancestral population sizes in hominoids using data from multiple loci. Genetics 2002, 162:1811-1823.

69. Wong WS, Nielsen R: Detecting selection in noncoding regions of nucleotide sequences. Genetics 2004, 167:949-958.

70. Yang Z, Wong WSW, Nielsen R: Bayes empirical Bayes inference of amino acid sites under positive selection. Mol Biol Evol 2005, 22:1107-1118.

71. Liao PC, Lin TP, Lan WC, Chung JD, Hwang SY: Duplication of the class I cytosolic small heat shock protein gene and potential functional divergence revealed by sequence variations flanking the a-crystallin domain in the genus Rhododendron (Ericaceae). Ann Bot 2010, 105:57-69.

72. Zhou HB, Li SF, Deng ZY, Wang XP, Chen T, Zhang JS, Chen SY, Ling HQ, Zhang AM, Wang DW, Zhang XQ: Molecular analysis of three new receptor-like kinase genes from hexaploid wheat and evidence for their participation in the wheat hypersensitive response to stripe rust fungus infection. Plant J 2007, 52:420-434.

doi:10.1186/1471-2229-10-214

Cite this article as: Yu et al:: Molecular analysis of

phosphomannomutase (PMM) genes reveals a unique PMM duplication event in diverse Triticeae species and the main PMM isozymes in bread wheat tissues. BMC Plant Biology 2010 10:214.

\section{Submit your next manuscript to BioMed Central and take full advantage of:}

- Convenient online submission

- Thorough peer review

- No space constraints or color figure charges

- Immediate publication on acceptance

- Inclusion in PubMed, CAS, Scopus and Google Scholar

- Research which is freely available for redistribution 